\title{
High-performance salt-resistant solar interfacial evaporation by flexible robust porous carbon/pulp fiber membrane
}

\author{
Liang $\mathrm{Hao}^{1}$, Ning Liu ${ }^{1}$, Ran Niu ${ }^{1}$, Jiang Gong ${ }^{{ }^{*}}$ and Tao Tang ${ }^{2 *}$
}

\begin{abstract}
Solar evaporation has emerged as an attractive technology to produce freshwater by utilizing renewable solar energy. However, it remains a huge challenge to develop efficient solar steam generators with good flexibility, low cost and remarkable salt resistance. Herein, we prepare flexible, robust solar membranes by filtration of porous carbon and commercial paper pulp fiber. The porous carbon with well-defined structures is prepared through controlled carbonization of biomass/waste plastics by eutectic salts. We prove the synergistic effect of porous carbon and paper pulp fiber in boosting solar evaporation performance. Firstly, the porous carbon displays a high light absorption, while the paper pulp fiber with good hydrophilicity effectively promotes the transport of water. Secondly, the combination between porous carbon and paper pulp fiber reduces the water vaporization enthalpy by $20 \%$, which is important to significantly improve the evaporation performance. As a proof of concept, the porous carbon/paper pulp fiber membrane possesses a high evaporation rate of $1.8 \mathrm{~kg} \mathrm{~m}^{-2} \mathrm{~h}^{-1}$ under $1 \mathrm{~kW} \mathrm{~m}^{-2}$ irradiation. Thirdly, the good flexibility and mechanical property of paper pulp fiber enable the solar membrane to work well under extreme conditions (e.g., after 20 cycles of folding/stretching/ recovery). Lastly, due to the super-hydrophilicity and superwetting, the hybrid membrane exhibits the exceptional salt resistance and long-term stability in continuous seawater desalination, e.g., for $50 \mathrm{~h}$. Importantly, a large-scale solar desalination device for outdoor experiments is developed to produce freshwater. Consequently, this work provides a new insight into developing advanced flexible solar evaporators with superb performance in seawater desalination.
\end{abstract}

Keywords: solar steam generation, porous carbon, flexible evaporator, pulp fiber, salt resistance

\section{INTRODUCTION}

Nowadays, energy crisis and freshwater scarcity have become two of the most severe problems that threaten human survival and restrict societal development [1]. Solar technology and seawater desalination have been considered as feasible solutions to tackle these two problems $[2,3]$. Extensive efforts have been made to exploit solar energy for producing freshwater from seawater through evaporation [4,5]. Among the existing solar desalination technologies, interfacial solar steam generation (ISSG) has recently attracted great attention because of high solar-to-vapor conversion efficiency [6-9]. As a pivotal component of ISSG system, solar absorber acts as photo-thermal converter to provide thermal energy for water evaporation $[10,11]$. Until now, various types of solar absorbers have been developed, including metal nanoparticles [12-16], semi-conductor material [17], conjugated polymer [18], carbon material [19-23], and hydrogel [24,25]. Despite the significant progress achieved, these absorbers usually show drawbacks of high cost and complex synthesis process.

As promising solar absorbers, carbon materials have recently attracted great interest owing to their low cost, excellent light absorption, high photo-thermal conversion efficiency, and chemical stability [10,26-31]. However, traditional carbon materials are often intrinsically fragile, especially in powder state. Therefore, fabrication of robust and flexible carbon material-based absorbers is highly needed for practical solar evaporation. Xu et al. [32] reported a monolithic carbon-based solar absorber by carbonization of mushroom. The monolithic carbon possessed a stable structure and displayed a conversion efficiency of $78 \%$ under $1 \mathrm{~kW} \mathrm{~m}^{-2}$ irradiation. Qiu et al. [33] carbonized wood to prepare a three-dimensional carbon foam, which exhibited good stability for solar desalination. Wang et al. [30] reported the carbonization of potato slices to prepare carbon foams with a high conversion efficiency of $86 \%$ under $1 \mathrm{~kW} \mathrm{~m}^{-2}$ irradiation. Nevertheless, most of these carbon material-based solar evaporators showed low evaporation rates (e.g., $<1.6 \mathrm{~kg} \mathrm{~m}^{-2} \mathrm{~h}^{-1}$ ); meanwhile, the roles of different pores (including micropores, mesopores and macropores) of carbon materials are still controversial on water transportation and vaporization enthalpy. From the viewpoints of both academic and industrial communities, facile fabrication of robust, flexible carbon-based absorbers with well-defined pores is greatly challenging, but also urgently needed to achieve high evaporation rates and expound the roles of porous structures.

Another challenge of carbon-based absorbers during seawater evaporation is salt crystallization owing to the low hydrophilicity of carbon, which impedes water transport and reduces the

\footnotetext{
${ }^{1}$ Key Laboratory of Material Chemistry for Energy Conversion and Storage, Ministry of Education, Hubei Key Laboratory of Material Chemistry and Service Failure, Hubei Engineering Research Center for Biomaterials and Medical Protective Materials, School of Chemistry and Chemical Engineering, Huazhong University of Science and Technology, Wuhan 430074, China

${ }^{2}$ State Key Laboratory of Polymer Physics and Chemistry, Changchun Institute of Applied Chemistry, Chinese Academy of Sciences, Changchun 130022, China

*Corresponding authors (emails: gongjiang@hust.edu.cn (Gong J); ttang@ciac.ac.cn (Tang T))
} 
evaporation rate. Consequently, carbon materials are often combined with natural hydrophilic matrix (e.g., wood) to construct carbon-based hybrid absorbers with high hydrophilicity [34-37]. Chao et al. [38] prepared a photothermal evaporation system by depositing a layer of carbon dots on the surface of wood, which showed good stability in solar desalination. Kim et al. [39] fabricated a graphene-coated wood bilayer solar evaporator, which displayed a solar-to-vapor conversion efficiency of $92 \%$ and an evaporation rate of $1.64 \mathrm{~kg} \mathrm{~m}^{-2} \mathrm{~h}^{-1}$ under $1 \mathrm{~kW} \mathrm{~m}^{-2}$ irradiation. However, during long-term seawater desalination, the carbon-coated wood absorbers still face a high risk of salt precipitation, since the evaporation surface of carbon layer usually could not quickly replenish the vaporized salt water. Besides, these absorbers lack enough flexibility for practical processing and transportation. In this context, cellulose fiber-based materials (e.g., paper pulp fiber), which display advantages of renewability, low cost, excellent hydrophilicity, and good flexibility, become more promising choices to construct efficient, salt-resistant solar absorbers by combining with carbon materials. Unfortunately, to the best of our knowledge, there have been no reports on solar evaporators prepared by porous carbon/paper pulp fiber.

In this work, we report the fabrication of free-standing, flexible porous carbon/paper pulp fiber membrane for efficient, durable solar evaporation and desalination. The porous carbon with well-defined porous structures is prepared by carbonization of waste polymers with the assistance of $\mathrm{ZnCl}_{2} / \mathrm{NaCl} . \mathrm{ZnCl}_{2} /$ $\mathrm{NaCl}$ eutectic salt acts as an pore-forming agent to construct micro-/meso-/macro-pores, and catalyze the de-hydration and de-carboxylation of poly(ethylene terephthalate) (PET) intermediate degradation products to form the carbon framework. The low-cost paper pulp fiber is obtained from paper industry. Thanks to the synergistic effect of porous carbon and paper pulp fiber, the as-prepared porous carbon/paper pulp fiber hybrid membrane exhibits excellent light absorption, high photo-thermal conversion efficiency, super-wettability, super-hydrophilicity, and good flexibility. The features above endue the hybrid solar membrane with high evaporation performance and long-term salt resistance in seawater desalination.

\section{EXPERIMENTAL SECTION}

\section{Materials and chemicals}

PET was obtained from Usolf Chemical in Shandong (China). Sodium lignosulfonate (SLS) was bought from Xiya Chemical Company (China). Paper pulp fiber was bought from Hao Sheng Company (China). Other chemicals were supplied by Sinopharm Chemical Reagent Company (China). Seawater was obtained from the South Sea (China, Fig. S1).

\section{Preparation of porous carbon (PC-x)}

The synthesis process of porous carbon is illustrated in Fig. 1a. Firstly, $1 \mathrm{~g}$ PET and $0.5 \mathrm{~g}$ SLS were added into an alumina crucible. Next, a given amount of $\mathrm{ZnCl}_{2} / \mathrm{NaCl}$ eutectic salt (the ratio is 58/42, according to previous work [40]) was added and mixed evenly to gain PET/SLS-ZnCl $2 / \mathrm{NaCl}-x$ mixture $(x=0,1,3,10$ and 20), where $x$ represents the mass ratio of $\mathrm{ZnCl}_{2} / \mathrm{NaCl}$ to PET/SLS. The mixture was heated in a muffle furnace at $280^{\circ} \mathrm{C}$ for $10 \mathrm{~min}$ and then $550^{\circ} \mathrm{C}$ for $8 \mathrm{~min}$ with a ramp rate of $10^{\circ} \mathrm{C} \mathrm{min}^{-1}$. Finally, the product was purified by using hydrochloric acid and deionized water, dried and named as PC- $x$.

\section{Preparation of porous carbon/pulp fiber (PCP-x) membranes}

Typically, $0.50 \mathrm{~g}$ paper pulp fiber was firstly put in $25 \mathrm{~mL}$ deionized water and dispersed evenly. Subsequently, $40 \mathrm{mg}$ PC- $x$ was added into the pulp fiber dispersion and stirred vigorously for $5 \mathrm{~min}$. Afterwards, the dispersion was filtrated to obtain a free-standing porous carbon/pulp fiber membrane, which was dried overnight under ambient temperature and designated as PCP- $x$. In comparison, $0.50 \mathrm{~g}$ poly(vinylidene difluoride) (PVDF) fibers were added into $25 \mathrm{~mL}$ water and stirred evenly for $10 \mathrm{~min}$. Subsequently, $40 \mathrm{mg}$ PC-20 powder was added into the PVDF fiber dispersion. The resultant mixture was stirred for $10 \mathrm{~min}$ and filtrated to fabricate the PVDF/PC-20 membrane.

\section{Characterization}

Scanning electron microscopy (SEM, SU8010) was used to observe the morphology. The microstructure was characterized by high-resolution transmission electron microscope (HRTEM, Tecnai G2 F30). The specific surface area was analyzed by the Brunauer-Emmett-Teller (BET) method using an analyzer (Micromeritics ASAP 2460), and the pore size distribution was analyzed by using density functional theory (DFT) model or Barret-Joyner-Halenda (BJH) model. The crystalline structure was characterized by X-ray diffractometer (XRD, SmartLab-SE) and Raman microscope (inVia Reflex). The types of elements were characterized by X-ray photo-electron spectroscopy (XPS) with $\mathrm{Al} \mathrm{Ka}$ radiation. The wettability was studied with a contact angle measurement (Dataphysics OCA15EC). Optical absorption spectra were recorded on a UV-Vis spectrometer (Lambda 750S). Hot disk method was adopted to measure the thermal conductivity using Hot Disk TPS 2500s. The ion concentrations of seawater and distilled water were measured by using inductively coupled plasma optical emission spectrometer (ICP-OES, Agilent 720ES). Mercury intrusion porosimetry measurement was conducted to measure the porosity and pore size distribution using an Autopore V9600 device (Micromeritics). Optical image was obtained by using an optical microscope (Mshot, MS60).

\section{Solar evaporation and desalination}

Solar evaporation experiment was performed by using a xenon light source (CEL-S500L, CEAULIGHT, China) as the solar light simulator (Fig. S2). An electronic balance (accuracy $=1 \mathrm{mg}$, JA2003) was used to record the water mass change. The asprepared PCP- $x$ membrane was firstly cut into a round shape with a diameter of ca. $2.6 \mathrm{~cm}$. Next, the membrane was placed on a piece of polystyrene foam which was covered by hydrophilic silk to transport water molecules to the bottom of membrane. Herein, polystyrene foam was used as both support and thermal insulating layer. Before the evaporation, the light intensity was calibrated by using a light power meter (CEL-FZ-A, CEAULIGHT). The surface temperature of membrane was recorded by an infrared camera (DM-I220, Dongmei). During the indoor solar evaporation tests, the relative humidity of the environment was controlled as ca. $36 \%$ by using a dehumidifier (DYD-E12A3, Deye, China). Besides, seawater was used to study the desalination performance and salt-resistance of the membrane.

\section{RESULTS AND DISCUSSION}

\section{Morphologies and microstructures}

PC- $x$ was prepared by carbonization of PET/SLS mixture with 
a
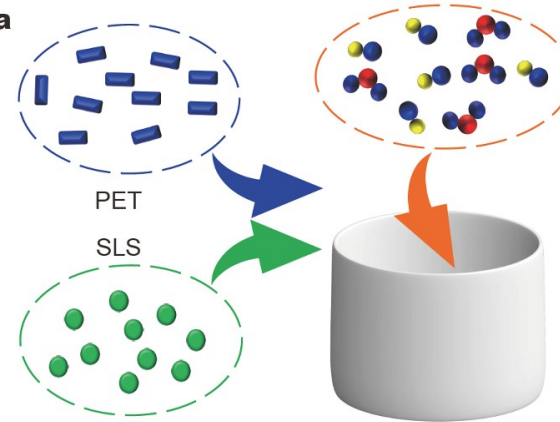
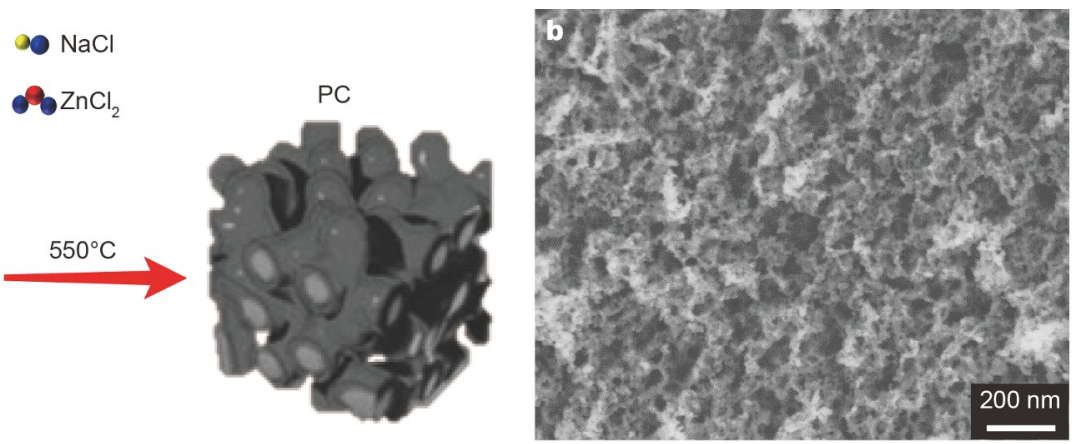
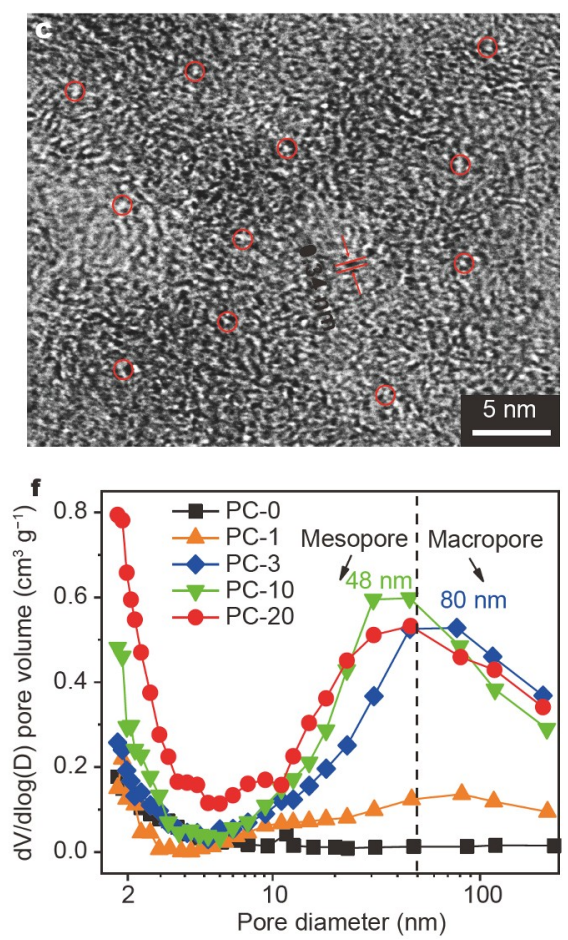
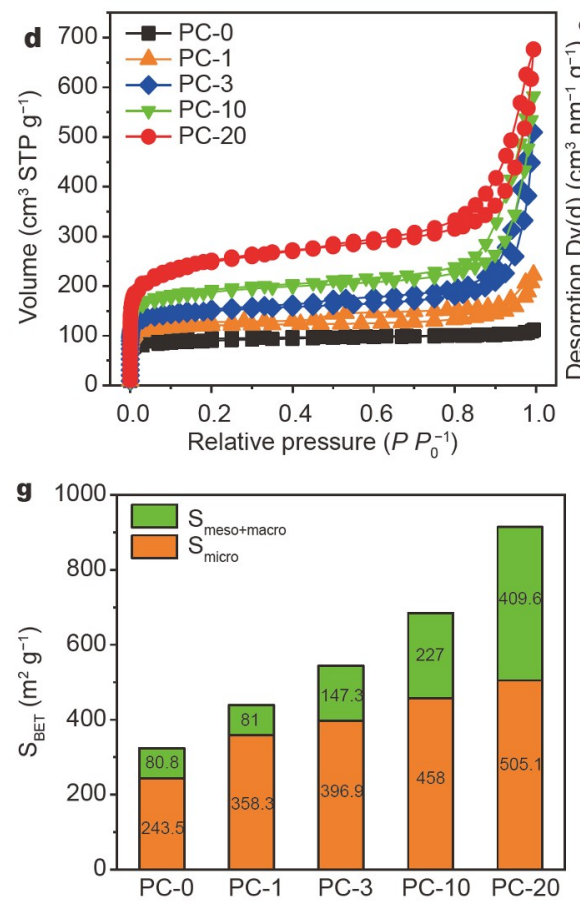

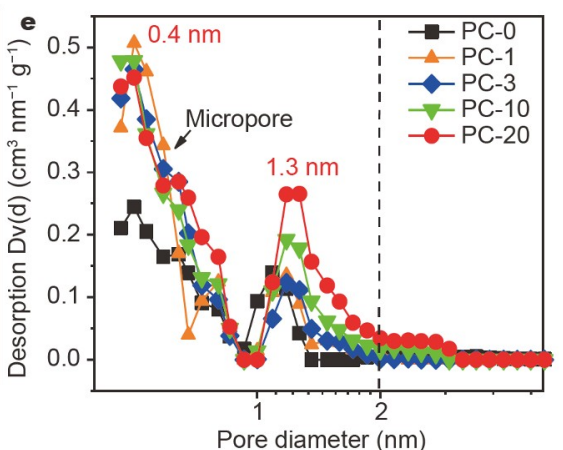

h

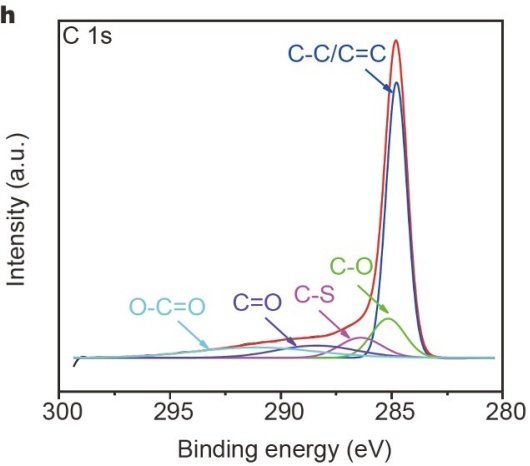

Figure 1 (a) Scheme of synthesizing PC from PET/SLS mixture using the molten salt method. (b) SEM and (c) HRTEM images of PC-20. (d) $\mathrm{N}_{2}$ physisorption isotherms of PC- $x$. Pore size distribution plots of PC- $x$ through (e) DFT model or (f) BJH model. (g) Comparison of $S_{\text {BET }}, S_{\text {micro }}$ and $S_{\text {meso }+ \text { macro }}$ of PC- $x$. (h) High-resolution C 1s XPS spectrum of PC-20.

the assistance of eutectic salt $\mathrm{ZnCl}_{2} / \mathrm{NaCl}$ at $550^{\circ} \mathrm{C}$ (Fig. 1a). The morphology of PC- $x$ was firstly observed by SEM. Typically, PC20 exhibits irregular and highly interconnected structures and bears a critical mass of nanopores with the size ranging from 20 to $80 \mathrm{~nm}$ (Fig. 1b). Evidently, the formation of nanopores is attributed to the implantation of $\mathrm{ZnCl}_{2} / \mathrm{NaCl}$ during carbonization. Meanwhile, element mapping images indicate that carbon and oxygen elements are homogeneously distributed in PC20 (Fig. S3).

In stark contrast to PC-20, PC-0 shows block-like morphology and smooth surface without any visible pores (Fig. S4a). The obviously lower apparent packing density of PC-20 than PC-0 (Fig. S4b) confirms that $\mathrm{ZnCl}_{2} / \mathrm{NaCl}$ remarkably affect the morphology of carbon products. HRTEM was used to further study the microstructure of PC-20 (Fig. 1c). PC-20 possesses many micropores with the pore size of less than $2 \mathrm{~nm}$ and discontinuous lattice fringes with interplanar spacings of ca. $0.34 \mathrm{~nm}$.

The porous structure of PC- $x$ was measured by $\mathrm{N}_{2}$ adsorption- desorption isotherms. PC- $x(x=1,3,10$ and 20) exhibit the combination of type I/IV isotherms with a type-H4 hysteresis loop (Fig. 1d), indicating that PC- $x$ possesses a wealth of micropores and mesopores. In comparison, PC-0 displays a type-I curve, suggesting the presence of only micropores in PC0 . The pore size distribution plot was explored by using DFT model or $\mathrm{BJH}$ model. The pore size distribution of microporous structures is centered at ca. 0.4 and $1.3 \mathrm{~nm}$ (Fig. 1e). Obviously, the presence of $\mathrm{ZnCl}_{2} / \mathrm{NaCl}$ introduces many mesopores and marcopores in a size range of $20-80 \mathrm{~nm}$ (Fig. 1f), which is in line with the SEM results. Fig. 1g summarizes the BET surface areas of PC- $x$. Upon increasing the quantity of $\mathrm{ZnCl}_{2} / \mathrm{NaCl}$, the specific surface area $\left(S_{\mathrm{BET}}\right)$, specific surface area of micropore $\left(S_{\text {micro }}\right)$, and specific surface area of mesopore/macropore $\left(S_{\text {meso+macro }}\right)$ go up significantly. Hence, the specific surface area and pore size of PC- $x$ could be controlled by adjusting the amount of $\mathrm{ZnCl}_{2} / \mathrm{NaCl}$.

The crystal structures and elemental compositions of PC-0 and PC-20 were studied by XRD, Raman spectra and XPS. As 
shown in Fig. S5a, the broad peak (002) at $2 \theta=23^{\circ}$ suggests the presence of disordered and amorphous structures in PC-0 and PC-20. Fig. S5b exhibits Raman spectra of PC-0 and PC-20. Two characteristic peaks at $1343 \mathrm{~cm}^{-1}$ (D band) and $1591 \mathrm{~cm}^{-1}$ (G band) are related to the ordered carbon and the defective carbon, respectively [41]. Raman curve fittings of D and $G$ bands are shown in Fig. $S 5 c$ and $S 5 d$. The $I_{\mathrm{D}} / I_{\mathrm{G}}$ ratio is calculated by the area ratio of the fitted $\mathrm{D}$ band to the fitted $\mathrm{G}$ band. Notably, PC20 has a higher $I_{\mathrm{D}} / I_{\mathrm{G}}$ ratio (2.23) than PC-0 $\left(I_{\mathrm{D}} / I_{\mathrm{G}}=2.03\right)$, suggesting the existence of more disordered structures in PC-20 $[42,43]$. It is probably because PC-20 owns more pores. The survey scan XPS curve confirms the presence of $\mathrm{C}, \mathrm{O}$ and $\mathrm{S}$ elements in PC-20 (Fig. S6a). The high-resolution C 1s XPS spectrum of PC-20 consists of five single peaks (Fig. 1h), including $\mathrm{O}-\mathrm{C}=\mathrm{O}(292.6 \mathrm{eV}), \mathrm{C}=\mathrm{O}(288.1 \mathrm{eV}), \mathrm{C}-\mathrm{S}(286.2 \mathrm{eV})$, $\mathrm{C}-\mathrm{O}(285 \mathrm{eV})$ and $\mathrm{C}-\mathrm{C} / \mathrm{C}=\mathrm{C}(284.6 \mathrm{eV})[44,45]$. Moreover, three individual peaks appear at $536.2,533.8$ and $532.3 \mathrm{eV}$ in the highresolution $\mathrm{O}$ 1s XPS spectrum (Fig. S6b), corresponding to $\mathrm{C}=\mathrm{O}$, $\mathrm{C}-\mathrm{O}-\mathrm{C}$ and $\mathrm{C}-\mathrm{OH}$, respectively [46]. As such, $\mathrm{PC}-20$ bears rich oxygen-containing functional groups, similar with PC-0 (Fig. S7).

Subsequently, flexible, free-standing PC- $x$ /paper pulp fiber $(\mathrm{PCP}-x)$ membranes were prepared by vacuum filtration of PC- $x$ and paper pulp fiber (Fig. 2a). The paper pulp fiber shows a diameter of 10-30 $\mu \mathrm{m}$ (Fig. S8a) and possesses some gullies and small defects on the surface (Fig. 2b), which favor the loading of carbon nanoparticles. Typically, PCP-20 membrane is composed of numerous PC-20 nanoparticles adhered on the surface of paper pulp fiber. The majority of PC-20 nanoparticles are well distributed in gullies and defects of pulp fiber (Fig. 2c, d), despite of some agglomerates of PC-20 nanoparticles (Fig. S8b). The good distribution of PC-20 nanoparticles is probably due to the strong interaction of PC-20 nanoparticles with paper pulp fiber.
As well-known, paper pulp fiber has many hydrophilic functional groups (e.g., hydroxyl) and exhibits a high hydrophilicity. As a proof of concept, the contact angle of paper pulp fiber is as low as $39^{\circ}$, and the water droplet remains for only $0.1 \mathrm{~s}$ (Fig. S9). The introduction of PC-20 nanoparticles has no obvious effects on the hydrophilicity of paper pulp fiber, and the as-prepared PCP-20 membrane exhibits a good wettability with an initial water contact angle of $41^{\circ}$ (Fig. 2e and Video S1), which is likely related to the rich hydrophilic functional groups of PC-20 nanoparticles.

\section{Solar steam generation}

During evaporation, the good photo-thermal conversion capability is important for solar absorbers. Hence, the light absorption spectra of PCP-20 membrane and paper pulp fiber over a range of 300-2500 nm were firstly investigated. According to the optical absorption spectra (Fig. 3a), PCP-20 exhibits an average light absorption of ca. $90 \%$, which is significantly higher than that of paper pulp fiber (ca. $40 \%$ ). It is contributed to the multiple light scattering of PC-20 nanoparticles with abundant pores. The excellent light absorption ensures PCP-20 to harvest solar energy for heating water during solar evaporation. Fig. $3 \mathrm{~b}$ shows the surface temperatures of PCP-20 membrane and paper pulp fiber in dry state under $1 \mathrm{~kW} \mathrm{~m}^{-2}$ irradiation. The surface temperature of PCP-20 increases rapidly from ca. 35.3 to $81.9^{\circ} \mathrm{C}$ and remains at $\mathrm{ca} .82 .1^{\circ} \mathrm{C}$. In contrast, the surface temperature of paper pulp fiber rises slowly to ca. $52.3^{\circ} \mathrm{C}$, which is remarkably lower than that of PCP-20. Similar phenomena are observed in PCP-20 and paper pulp fiber in wet state (Fig. S10). Fig. 3c, d show infrared images of paper pulp fiber and PCP-20 upon different irradiation times. The results above prove that PCP-20 displays high photo-thermal conversion performance. Besides, the thermal conductivity of PCP-20 in dry state is as low as
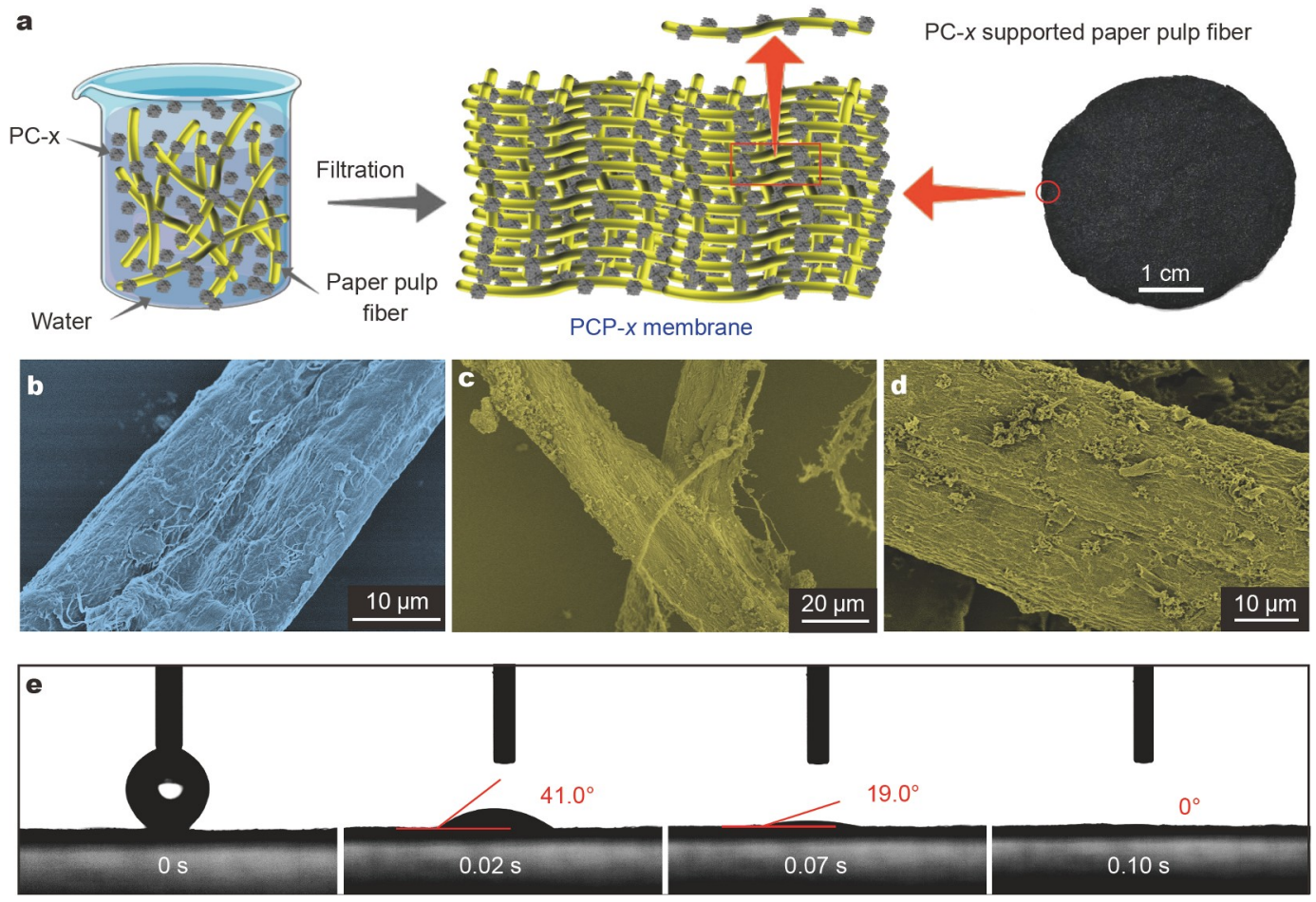

Figure 2 (a) Scheme of preparing PCP- $x$ membranes. SEM images of (b) paper pulp fiber and (c, d) PCP-20 membrane. (e) Time evolution of the water contact angles of PCP-20. 

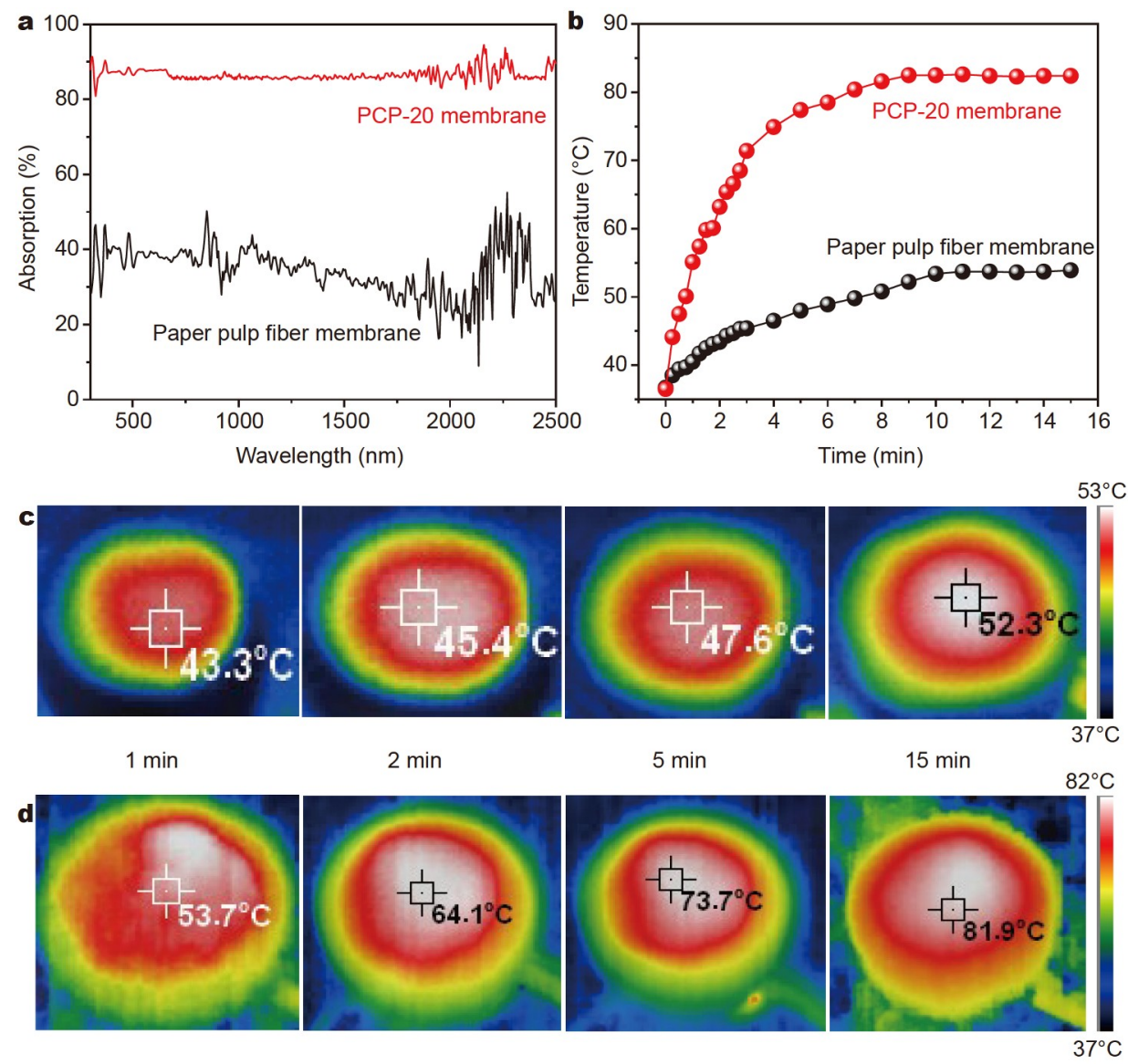

Figure 3 (a) Absorbance spectra and (b) temperature evolution under $1 \mathrm{~kW} \mathrm{~m}^{-2}$ irradiation of PCP-20 and paper pulp fiber. Infrared images of (c) paper pulp fiber and (d) PCP-20 under $1 \mathrm{~kW} \mathrm{~m}^{-2}$ irradiation.

$0.154 \mathrm{~W} \mathrm{~m}^{-1} \mathrm{~K}^{-1}$, which can reduce the conductive heat loss during solar evaporation [47]. By comprehensive consideration on the terms of good wetting property, good photo-thermal conversion capability, and low thermal conductivity, PCP-20 can be regarded as a promising candidate for solar steam generation [48].

To study the performance of solar steam generation, the water mass changes of PCP-20 membranes with different PC-20 dosages of $0-60 \mathrm{mg}$ were recorded under $1 \mathrm{~kW} \mathrm{~m}^{-2}$ irradiation. All of the samples show a linear relationship between water mass change and irradiation time (Fig. 4a). When the PC-20 dosage increases from 0 to $40 \mathrm{mg}$, the evaporation rate increases significantly from 0.98 to $1.8 \mathrm{~kg} \mathrm{~m}^{-2} \mathrm{~h}^{-1}$ (Fig. $4 \mathrm{~b}$ ). Obviously, the addition of PC-20 nanoparticles remarkably improves the performance of solar steam generation. However, the evaporation rate of PCP-20 stages with further increasing PC-20 dosage to $60 \mathrm{mg}$, likely because the addition of excessive porous carbon affects water transport. For comparison, the evaporation rates of water in the dark and without absorbers are 0.4 and $0.86 \mathrm{~kg} \mathrm{~m}^{-2} \mathrm{~h}^{-1}$, respectively (Fig. S11). The evaporation efficiency $(\eta, \%)$ and enhancement factor (EF) are calculated as follows [49-52]:

$\eta=m^{\prime} \times h_{\mathrm{Lv}} / 3600 P_{\mathrm{in}}$

$\mathrm{EF}=m$ (absorber) $/ m$ (blank),

where $m^{\prime}$ is the evaporation rate after subtracting the evaporation rate in the dark $\left(\mathrm{kg} \mathrm{m}^{-2} \mathrm{~h}^{-1}\right), h_{\mathrm{Lv}}$ represents the water vaporization enthalpy $\left(\mathrm{J} \mathrm{g}^{-1}\right), P_{\text {in }}$ stands for the light intensity $\left(1 \mathrm{~kW} \mathrm{~m}^{-2}\right)$, and $m$ (blank) means the evaporation rate measured without absorbers. As exhibited in Fig. 4c, the conversion efficiency of PCP-20 membrane containing 0, 10, 20 and $40 \mathrm{mg}$ PC20 is calculated as $42.4 \%, 72.7 \%, 82.6 \%$ and $87.6 \%$, respectively. Additionally, PCP-20 membrane with the PC-20 dosage of $40 \mathrm{mg}$ shows the highest enhancement factor (2.11).

More importantly, PCP-20 is superior to many recently reported absorbers in terms of the evaporation rate (Fig. $4 \mathrm{~d}$ and Table S1), such as carbon foam $\left(1.48 \mathrm{~kg} \mathrm{~m}^{-2} \mathrm{~h}^{-1}\right)$ [30], GO/PVA EFMs $\left(1.42 \mathrm{~kg} \mathrm{~m}^{-2} \mathrm{~h}^{-1}\right)$ [53], TiN/carbon foam $\left(1.47 \mathrm{~kg} \mathrm{~m}^{-2} \mathrm{~h}^{-1}\right)$ [54], and reduced graphene oxide foam $\left(1.48 \mathrm{~kg} \mathrm{~m}^{-2} \mathrm{~h}^{-1}\right)$ [55]. Thereby, PCP-20 membrane containing $40 \mathrm{mg}$ PC-20 possesses excellent performance in solar steam generation (the inset of Fig. 4d and Video S2), and is selected to carry out further research on solar evaporation. Fig. 4e displays the effect of irradiation density on the evaporation performance of PCP-20. The water mass change exhibits a linear trend with irradiation time. When the irradiation intensity is set as $0.5,1,2$ and 3 Sun, the evaporation rate is $1.13,1.80,3.42$ and $5.27 \mathrm{~kg} \mathrm{~m}^{-2} \mathrm{~h}^{-1}$, respectively (Fig. 4f).

Such high evaporation rate of PCP-20 membrane is supposed to be related to the reduced water vaporization enthalpy. To confirm this assumption, we measured the mass change of water in the dark and then calculated the corresponding enthalpy values. As shown in Fig. 5, the water mass changes within 60 min by using pure water, paper pulp fiber and PCP-20 are measured to be 212,245 and $259 \mathrm{mg}$, respectively. Consequently, PCP-20 

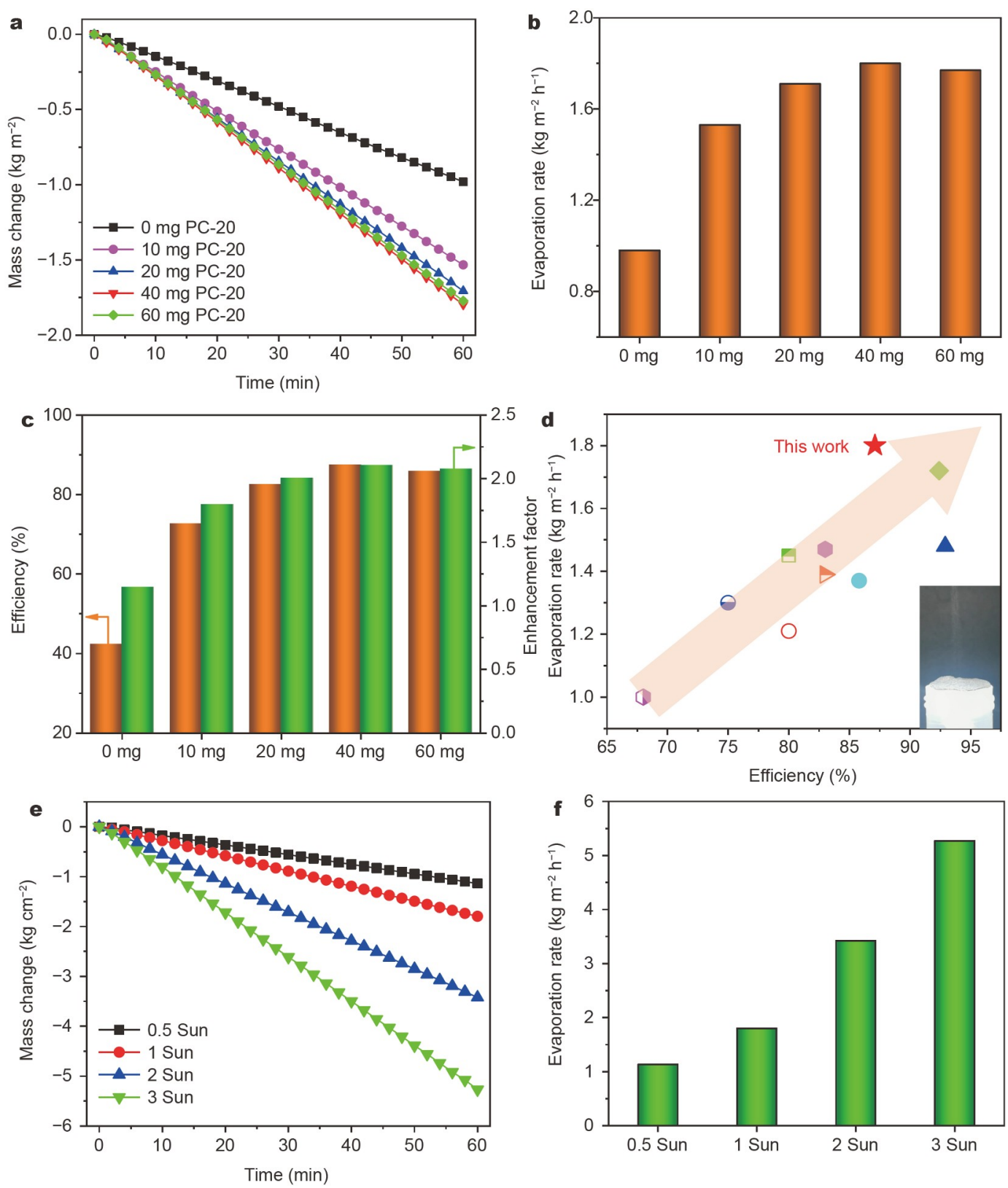

Figure 4 (a) Mass changes in water evaporation under $1 \mathrm{~kW} \mathrm{~m}^{-2}$ irradiation, (b) evaporation rates, (c) conversion efficiency and enhancement factors of PCP-20 with different PC-20 dosages. (d) Comparison of PCP-20 with some recently reported solar evaporators. Inset: digital image of solar steam generation of PCP-20 containing $40 \mathrm{mg}$ PC-20. (e) Time-dependent water mass changes and (f) evaporation rates of PCP-20 containing $40 \mathrm{mg}$ PC-20 under different illumination conditions.

shows the lowest water vaporization enthalpy $\left(1985 \mathrm{Jg}^{-1}\right)$, compared with paper pulp fiber membrane $\left(2087 \mathrm{Jg}^{-1}\right)$ and pure water $\left(2422 \mathrm{Jg}^{-1}\right)$. The results above indicate the synergistic effect of paper pulp fiber and PC-20 nanoparticles on the reduction of water vaporization enthalpy.

Based on the above results, the solar steam generation mechanism of PCP-20 membrane is put forward (Fig. 6), which is closely related to the synergistic effect between paper pulp fiber and PC-20 nanoparticles. Firstly, thanks to many voids with a wide size range of $10-150 \mu \mathrm{m}$ among paper pulp fibers (Figs S12 and S13), water molecules can enter the interior of the absorber substrate and then transport to the surface of absorber during solar evaporation (Fig. 6b). When bulk water transports in paper pulp fiber, part of water molecules combine with hydrophilic hydroxyl groups of paper pulp fiber through hydrogen bonds to form the bound water. The formation of the bound water weakens the strength of hydrogen bond between the bound water and nearby water molecules, which favors the reduction of the overall energy demanded for water evaporation (Fig. 6c) [56,57]. A similar phenomenon was observed in the corn stalk evaporator [58], in which part of water molecules formed hydrogen bonds with hydrophilic groups of the corn stalk to weaken the van der Waals force between water molecules, leading to the reduction of the water evaporation enthalpy by ca. $60 \%$.

Moreover, PC-20 nanoparticles display a good photo-thermal conversion effect and localize thermal energy to reduce heat loss (16\%, Note S1 in the Supplementary information). Meanwhile, 
the porous structures of PC-20 nanoparticles effectively divide bulk water to some smaller water clusters due to the space confinement effect (Fig. 6d), which reduces the density of hydrogen bonds between water molecules to further reduce the water vaporization enthalpy. Similarly, Dong et al. [59] recently proved that the formation of water clusters in $\mathrm{UiO}-66-\mathrm{COOH}$ nanochannels drastically reduced the water evaporation enthalpy by ca. $45 \%$. Accordingly, the marriage of paper pulp fiber and porous carbon nanoparticles effectively improves the water evaporation performance.

\section{Effect of porous structures on solar steam generation}

To unravel the influence of porous structures of carbon materials on the solar steam evaporation, PC- $x$ with well-defined porous structures were used to fabricate PCP- $x$ solar membranes. Fig. 7a shows the evaporation rates of PCP- $x$ under $1 \mathrm{~kW} \mathrm{~m}^{-2}$ irradiation. Clearly, PCP-20 exhibits the highest evaporation rate. To build an appropriate relationship between the evaporation rate and pore size, linear correlations between the evaporation rate and specific surface area of different pores (including $S_{\mathrm{BET}}, S_{\text {micro }}$ and $S_{\text {meso+macro }}$ ) are established, as shown in Fig. 7b-d. Linear correlation coefficients $\left(R^{2}\right)$ between the evaporation rate and $S_{\mathrm{BET}}, S_{\text {micro }}$ and $S_{\text {meso+macro }}$ are $0.868,0.845$ and

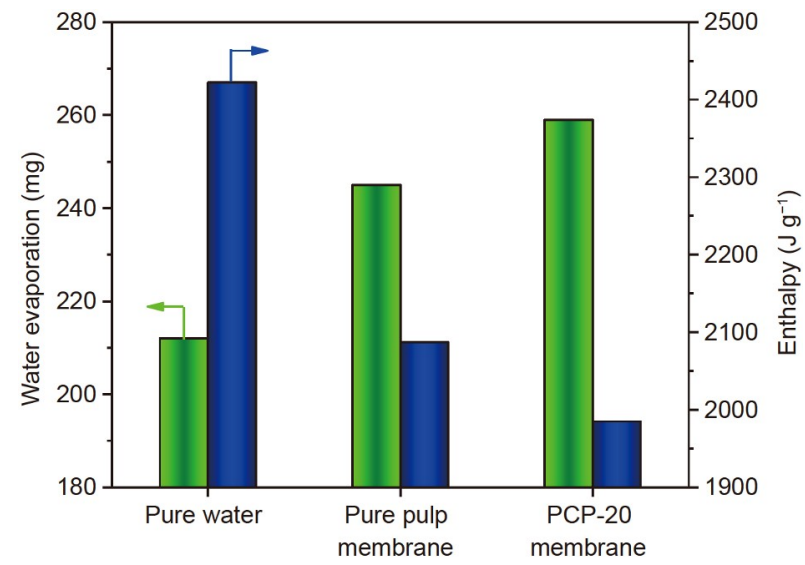

Figure 5 Comparison of the water mass changes in the dark and enthalpy values of different samples.
0.778, respectively. Consequently, micropores, mesopores and macropores indeed play important roles during solar evaporation. The better linear relationship is obtained from the evaporation rate and $S_{\text {micro, }}$ proving that microporous structures have more positive effects on water evaporation than mesoporous and marcoporous structures. The possible reason is that micropores with a size of $0.5-2 \mathrm{~nm}$ can divide bulk water into small clusters consisting of $2-5$ water molecules (ca. $0.33 \mathrm{~nm}$ ) owing to the space confinement effect. Evidently, the formed water clusters bear a lower density of hydrogen bonds than that of bulk water, resulting in the reduction of water evaporation enthalpy in PC- $x$ nanoparticles.

\section{Stability, flexibility and salt-rejecting property}

Since the durability is critical for continuous operation, PCP-20 membrane was treated by ultra-sonication (power $=50 \mathrm{~W}$ ) for 10 min (Fig. 8a). Excitingly, PCP-20 exhibits little-to-no changes after ultra-sonication (Fig. 8b). When PCP-20 is taken out, the remaining water is colorless by naked eyes, and no carbon particles are observed (Fig. 8c). Upon the same ultra-sonication treatment (Fig. 8d), many PC-20 nanoparticles drop down from the PVDF fibers (Fig. 8e), and meanwhile, the color of water turns to black and some PVDF fibers also fall from the PVDF/ PC-20 membrane (Fig. 8f). The possible reason is due to the weak interaction of hydrophobic PVDF fibers with PC-20 nanoparticles with rich hydrophilic groups. Strikingly, the evaporation performance of treated PCP-20 membrane is close to that of the fresh one, while the evaporation rate of PVDF/PC-20 membrane is reduced by ca. $30 \%$ (Fig. 8g). From the above results, it is concluded that the combination of PC-20 and paper pulp fiber endows exceptional stability.

The flexibility and good mechanical property are other pursuits for photo-thermal absorbers, which bring advantages of portability and durability. As shown in Fig. 8h, PCP-20 membrane can be folded into different shapes and stretched by using a 100-g weight, and finally spontaneously recovers into the initial shape. After 20 folding/stretching/recovering cycles, the resultant PCP-20 membrane still shows high evaporation performance, which is close to the fresh one (Fig. 8i). The above results prove the good flexibility and mechanical property of PCP-20 membrane.
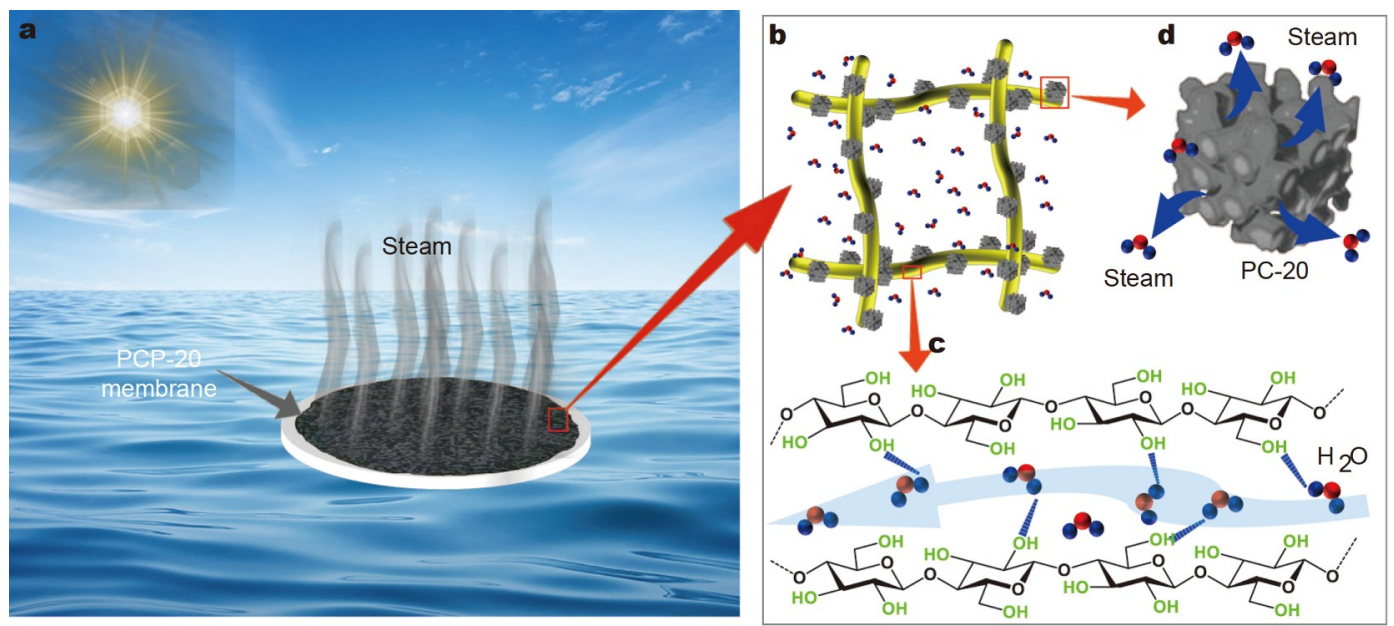

Figure 6 Schemes of (a) solar steam generation mechanism of PCP-20 membrane, and water transportation in (b) PCP-20 membrane or (c) paper pulp fiber. (d) Scheme of solar evaporation through PC-20 nanoparticles. 

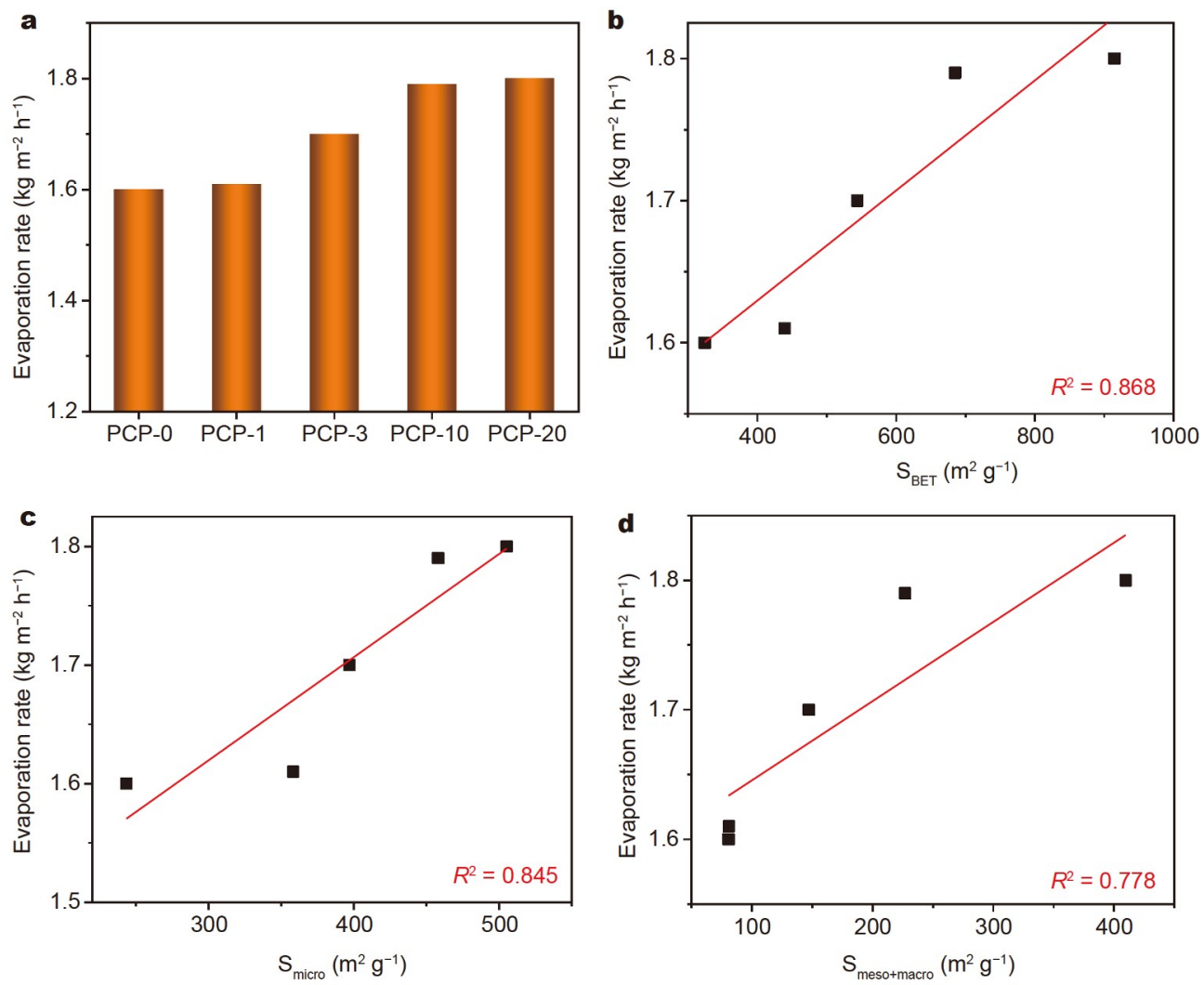

Figure 7 (a) Evaporation rates of PCP- $x$ membranes under $1 \mathrm{~kW} \mathrm{~m}^{-2}$ irradiation. Linear corrections between evaporation rate and specific surface area of different pores: (b) $S_{\mathrm{BET}}$, (c) $S_{\text {micro }}$ and (d) $S_{\text {meso+macro. }}$
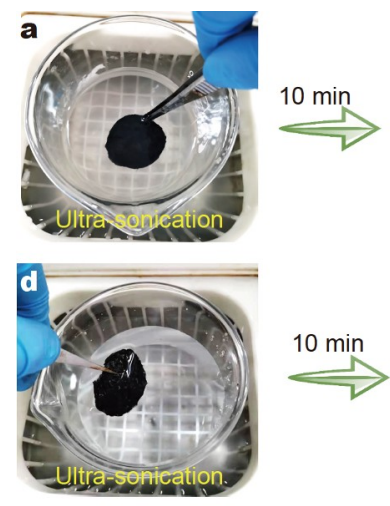

b

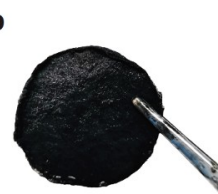

e
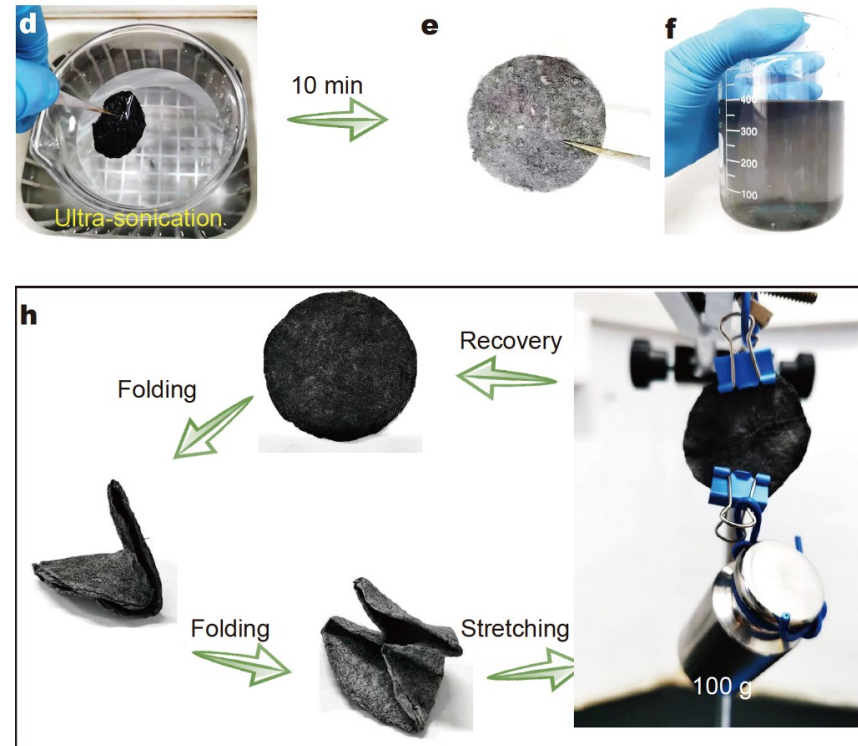
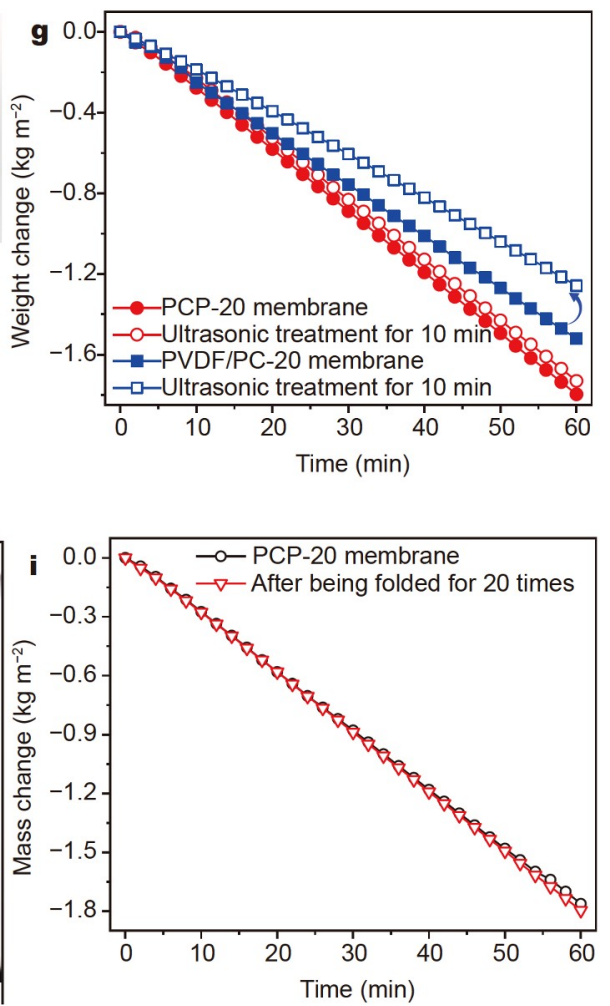

Figure 8 Stabilities of $(\mathrm{a}-\mathrm{c})$ PCP-20 and (d-f) PVDF/PC-20. (g) Mass changes in water evaporation using PCP-20 and PVDF/PC-20 before and after ultrasonication. (h) Optical images of PCP-20 after being folded, stretched and recovered. (i) Mass changes in water evaporation using fresh and treated PCP-20. 


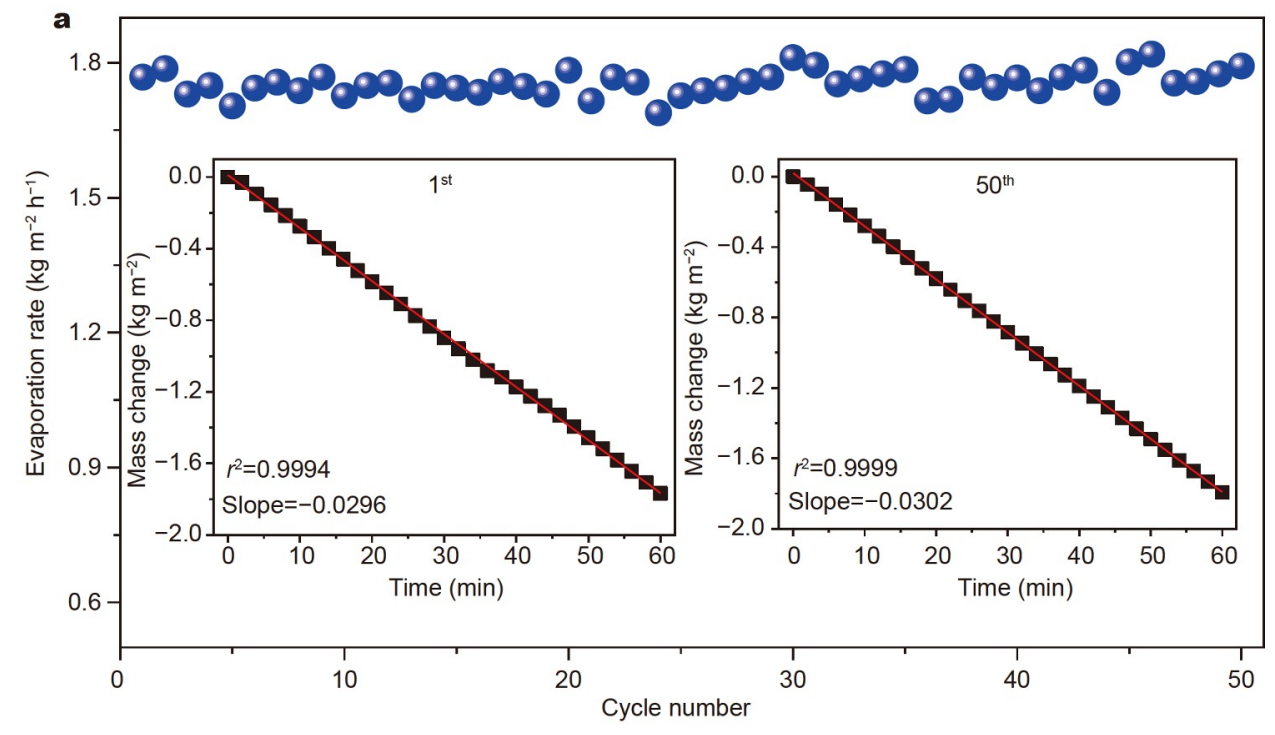

b
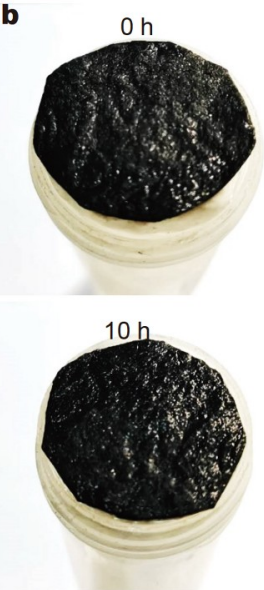
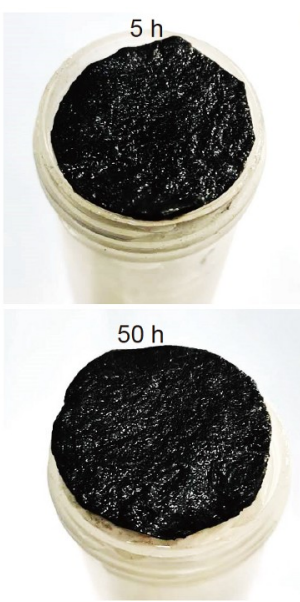

C
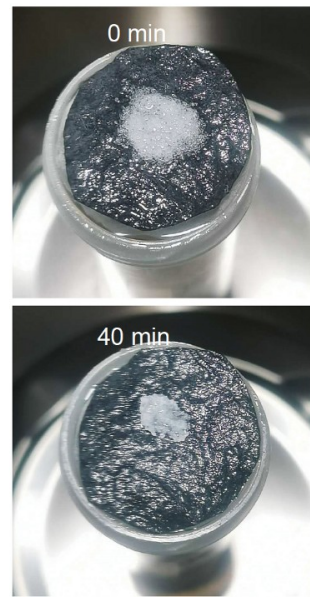
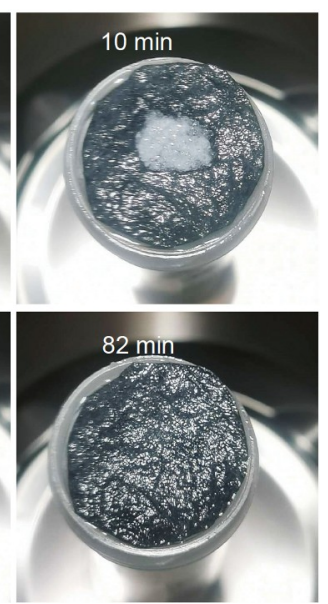

Figure 9 (a) Evaporation stability of PCP-20 in seawater for 50 cycles under $1 \mathrm{~kW} \mathrm{~m}{ }^{-2}$ irradiation. Insets show the water mass changes using PCP-20 in the 1 st and 50th cycles. (b) Digital images of PCP-20 after 0, 5, 10 and $50 \mathrm{~h}$ desalination tests. (c) Photographs of salt ablation process on the surface of PCP-20 under $1 \mathrm{~kW} \mathrm{~m}^{-2}$ irradiation.

The stability of solar evaporators during continuous operation under high-salt-concentration conditions is highly important for practical seawater desalination. The stability of PCP-20 was investigated for 50 cycles ( $1 \mathrm{~h}$ for each cycle). As shown in Fig. 9a, the evaporation rate of PCP-20 after 50 cycles keeps steady at ca. $1.8 \mathrm{~kg} \mathrm{~m}^{-2} \mathrm{~h}^{-1}$, which is close to that of the first cycle. The linear correlations of mass change profiles in the 1st and 50th cycles were fitted, and the corresponding slopes of the fitted lines are close. The stable evaporation rate indicates the desired performance of PCP-20 for long-term seawater desalination. Additionally, the top-view of the surface of PCP-20 was recorded through digital images (Fig. 9b). Upon 5, $10 \mathrm{~h}$ and even $50 \mathrm{~h}$, no salt particles are observed by naked eyes on the surface of PCP20 membrane. For further salt-rejecting experiment, the evaporation process was carried out in seawater under $1 \mathrm{~kW} \mathrm{~m}^{-2}$ irradiation, and solid $\mathrm{NaCl}(0.2 \mathrm{~g})$ was placed on the top surface of PCP-20. Interestingly, $\mathrm{NaCl}$ was completely dissolved after $82 \mathrm{~min}$ (Fig. 9c). Therefore, PCP-20 shows marvellous saltresistance property. It is because the excellent hydrophility of PCP-20 ensures water molecules to transport fast and arrive to the surface of membrane in time. The continuous flow of water to PCP-20 surface prevents salt crystallization. Meanwhile, the gaps among paper pulp fibers effectively promote the ablation of salt particles.

\section{Real-world solar seawater desalination}

A large-scale water evaporation system was designed to verify the practical seawater desalination performance of PCP-20. The evaporation device system consists of a water-evaporation-harvesting equipment and an agglomerated absorber (Fig. 10a). More specifically, the agglomerated absorber was assembled by 13 pieces of PCP-20 membranes (diameter $=4 \mathrm{~cm}$ ), with a total area of ca. $163 \mathrm{~cm}^{2}$ (Fig. S14). The water evaporation-harvesting equipment consists of evaporation room, water harvesting trough, and water outlet pipe (Fig. S14). The experiment was carried out on the roof of East Chemistry Building in the campus of Huazhong University of Science and Technology from 10:00 to $18: 00$ (October, 2020). In the process of water evaporation, the inwall of evaporation room is quickly covered by steam after ca. $4 \mathrm{~min}$, and many water drops are gathered on the inner 

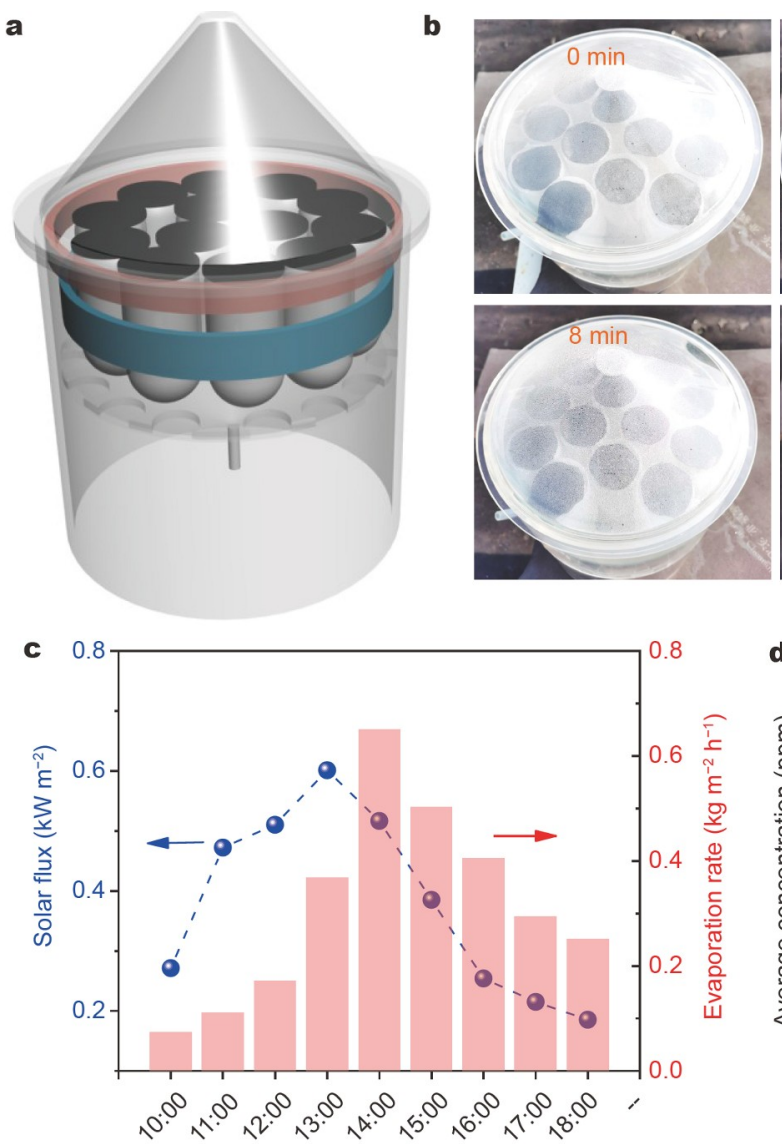
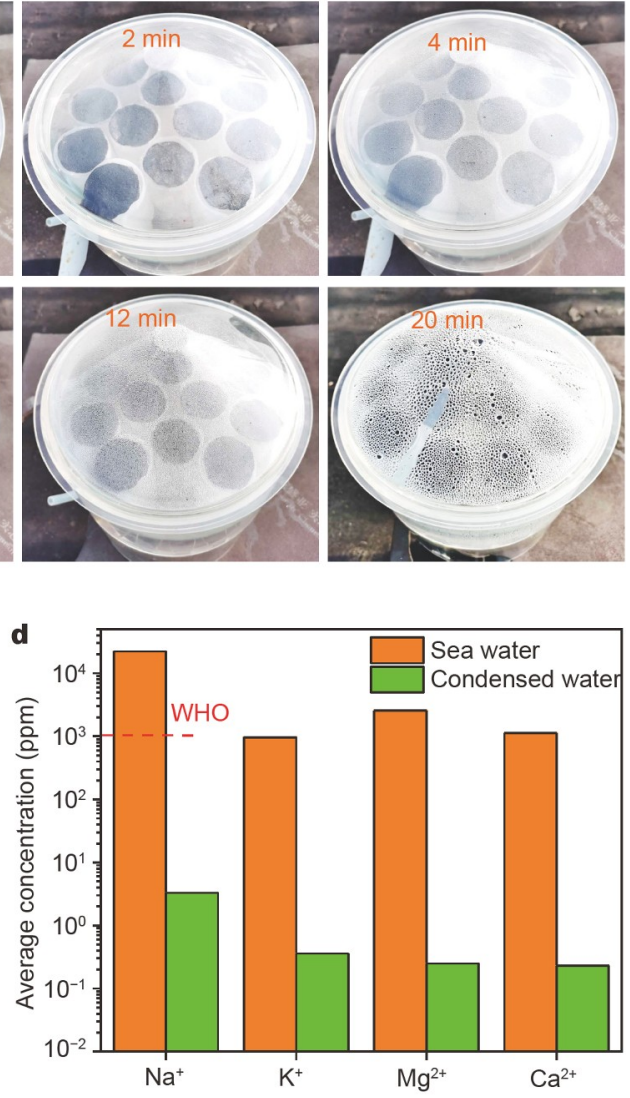

Figure 10 (a) Scheme of the large-scale water evaporation device. (b) Digital images of outdoor solar desalination device at different times. (c) Solar flux and evaporation rate $v s$. time. (d) Concentrations of metal ions in seawater and distilled water.

surface of evaporation room after $20 \mathrm{~min}$ (Fig. 10b). As shown in Fig. $10 \mathrm{c}$, under $0.15-0.6 \mathrm{~kW} \mathrm{~m}^{-2}$ solar flux, the evaporation rate reaches $0.65 \mathrm{~kg} \mathrm{~m}^{-2} \mathrm{~h}^{-1}$ with a water production of $2.83 \mathrm{~kg} \mathrm{~m}^{-2}$. Fascinatingly, the water harvested from each $1 \mathrm{~m}^{2}$ device can meet the demand of one person for a day (ca. 2.5 L). Notably, the concentration of $\mathrm{Na}^{+}$in gathered water after desalination (3.3 ppm) is sharply decreased by three orders of magnitude compared with the seawater $(22,197.9 \mathrm{ppm})$, and below the standard defined by the World Health Organization (WHO) [28,60-63]. The concentrations of other main ions (e.g., $\mathrm{K}^{+}$, $\mathrm{Mg}^{2+}$ and $\mathrm{Ca}^{2+}$ ) in the gathered water go down significantly (Fig. 10d), compared with those of seawater. Importantly, the cost of PCP-20 absorber is as low as ca. $¥ 1.42$ /piece (Table S2). Based on the results above, it can be concluded that the water evaporation system with PCP-20 exhibits outstanding performance and immense potential in practical seawater desalination.

\section{CONCLUSIONS}

In summary, we have prepared robust, flexible porous carbon/ paper pulp fiber hybrid membranes for high-performance, saltresistance solar evaporation. The porous carbon with well-controlled pore structures is prepared through carbonization of PET and SLS with the assistance of $\mathrm{ZnCl}_{2} / \mathrm{NaCl}$. Owing to the efficient light absorption of porous carbon and the excellent hydrophilic property of paper pulp fiber, the fabricated porous carbon/paper pulp fiber membrane exhibits excellent photothermal conversion ability and wettability. The evaporation rate and photo-thermal conversion efficiency under $1 \mathrm{~kW} \mathrm{~m}^{-2}$ irradiation are $1.8 \mathrm{~kg} \mathrm{~m}^{-2} \mathrm{~h}^{-1}$ and $87.6 \%$, respectively, which surpass many previous efficient photothermal materials. Such high performance originates from the synergistic effect between porous carbon and paper pulp fiber, which reduces the energy demand for water vaporization by ca. $20 \%$. Additionally, the micropores, mesopores and macropores play important roles during water evaporation process. The porous carbon/pulp fiber membrane not only exhibits high flexibility and mechanical property, but also shows remarkable stability and excellent saltresistant performance during seawater desalination. More importantly, a large-scale solar desalination device for outdoor experiments is developed to produce drinkable water from seawater. This work offers a scalable, cost-efficient path towards utilizing easily available and renewable paper pulp fiber and lowcost porous carbon from waste polymers for solar desalination and water purification. Future work on precisely controlling the porosity of porous carbons from waste polyesters is still needed to further reveal the roles of pores of carbon in the solar steam generation.

\section{Received 3 April 2021; accepted 28 May 2021;} published online 22 July 2021

1 Gao M, Zhu L, Peh CK, et al. Solar absorber material and system designs for photothermal water vaporization towards clean water and energy production. Energy Environ Sci, 2019, 12: 841-864

2 Elimelech M, Phillip WA. The future of seawater desalination: Energy, 
technology, and the environment. Science, 2011, 333: 712-717

3 Chu S, Majumdar A. Opportunities and challenges for a sustainable energy future. Nature, 2012, 488: 294-303

4 Wang Z, Horseman T, Straub AP, et al. Pathways and challenges for efficient solar-thermal desalination. Sci Adv, 2019, 5: eaax0763

5 Wang W, Shi Y, Zhang C, et al. Simultaneous production of fresh water and electricity via multistage solar photovoltaic membrane distillation. Nat Commun, 2019, 10: 3012

6 Tao P, Ni G, Song C, et al. Solar-driven interfacial evaporation. Nat Energy, 2018, 3: 1031-1041

7 Zhu L, Gao M, Peh CKN, et al. Recent progress in solar-driven interfacial water evaporation: Advanced designs and applications. Nano Energy, 2019, 57: 507-518

8 Chen C, Kuang Y, Hu L. Challenges and opportunities for solar evaporation. Joule, 2019, 3: 683-718

9 Zhou Y, Ding T, Gao M, et al. Controlled heterogeneous water distribution and evaporation towards enhanced photothermal waterelectricity-hydrogen production. Nano Energy, 2020, 77: 105102

10 Zhao F, Guo Y, Zhou X, et al. Materials for solar-powered water evaporation. Nat Rev Mater, 2020, 5: 388-401

11 Kashyap V, Ghasemi H. Solar heat localization: Concept and emerging applications. J Mater Chem A, 2020, 8: 7035-7065

12 Chen $\mathrm{C}$, Zhou L, Yu J, et al. Dual functional asymmetric plasmonic structures for solar water purification and pollution detection. Nano Energy, 2018, 51: 451-456

13 Yang Y, Yang X, Fu L, et al. Two-dimensional flexible bilayer Janus membrane for advanced photothermal water desalination. ACS Energy Lett, 2018, 3: 1165-1171

14 Gao M, Peh CK, Phan HT, et al. Solar absorber gel: Localized macronano heat channeling for efficient plasmonic Au nanoflowers photothermic vaporization and triboelectric generation. Adv Energy Mater, 2018, 8: 1800711

15 Wang C, Li Z, Wang W, et al. Greatly enhanced anticorrosion of Al$\mathrm{AlN}_{x} \mathrm{O}_{y}$ nanocermet films with self-passivated $\mathrm{Al}$ nanoparticles for enduring solar-thermal energy harvesting. J Mater Chem A, 2019, 7: 13080-13089

16 Meng FL, Gao M, Ding T, et al. Modular deformable steam electricity cogeneration system with photothermal, water, and electrochemical tunable multilayers. Adv Funct Mater, 2020, 30: 2002867

17 Zhu G, Xu J, Zhao W, et al. Constructing black titania with unique nanocage structure for solar desalination. ACS Appl Mater Interfaces, 2016, 8: 31716-31721

18 Chen Q, Pei Z, Xu Y, et al. A durable monolithic polymer foam for efficient solar steam generation. Chem Sci, 2018, 9: 623-628

19 Liu F, Zhao B, Wu W, et al. Low cost, robust, environmentally friendly geopolymer-mesoporous carbon composites for efficient solar powered steam generation. Adv Funct Mater, 2018, 28: 1803266

20 Zhang B, Song C, Liu C, et al. Molten salts promoting the "controlled carbonization" of waste polyesters into hierarchically porous carbon for high-performance solar steam evaporation. J Mater Chem A, 2019, 7: 22912-22923

21 Wang G, Fu Y, Guo A, et al. Reduced graphene oxide-polyurethane nanocomposite foam as a reusable photoreceiver for efficient solar steam generation. Chem Mater, 2017, 29: 5629-5635

22 Ming X, Guo A, Zhang Q, et al. 3D macroscopic graphene oxide/ MXene architectures for multifunctional water purification. Curr Alzheimer Resbon, 2020, 167: 285-295

23 Zhu HW, Ge J, Zhao HY, et al. Sponge-templating synthesis of sandwich-like reduced graphene oxide nanoplates with confined gold nanoparticles and their enhanced stability for solar evaporation. Sci China Mater, 2020, 63: 1957-1965

24 Zhao F, Zhou X, Shi Y, et al. Highly efficient solar vapour generation via hierarchically nanostructured gels. Nat Nanotech, 2018, 13: 489-495

25 Guo Y, Zhou X, Zhao F, et al. Synergistic energy nanoconfinement and water activation in hydrogels for efficient solar water desalination. ACS Nano, 2019, 13: 7913-7919

26 Han J, Dong Z, Hao L, et al. Poly(ionic liquid)-crosslinked graphene oxide/carbon nanotube membranes as efficient solar steam generators.
Green Energy Environ, 2021, doi: 10.1016/j.gee.2021.03.010

27 Yang Y, Zhao R, Zhang T, et al. Graphene-based standalone solar energy converter for water desalination and purification. ACS Nano, 2018, 12: $829-835$

28 Xiong ZC, Zhu YJ, Qin DD, et al. Flexible fire-resistant photothermal paper comprising ultralong hydroxyapatite nanowires and carbon nanotubes for solar energy-driven water purification. Small, 2018, 14: 1803387

29 Liu X, Cheng H, Guo Z, et al. Bifunctional, moth-eye-like nanostructured black titania nanocomposites for solar-driven clean water generation. ACS Appl Mater Interfaces, 2018, 10: 39661-39669

30 Wang C, Wang J, Li Z, et al. Superhydrophilic porous carbon foam as a self-desalting monolithic solar steam generation device with high energy efficiency. J Mater Chem A, 2020, 8: 9528-9535

31 Zhang Q, Xu W, Wang X. Carbon nanocomposites with high photothermal conversion efficiency. Sci China Mater, 2018, 61: 905-914

$32 \mathrm{Xu} \mathrm{N}, \mathrm{Hu} \mathrm{X}, \mathrm{Xu} \mathrm{W}$, et al. Mushrooms as efficient solar steamgeneration devices. Adv Mater, 2017, 29: 1606762

33 Qiu P, Liu F, Xu C, et al. Porous three-dimensional carbon foams with interconnected microchannels for high-efficiency solar-to-vapor conversion and desalination. J Mater Chem A, 2019, 7: 13036-13042

$34 \mathrm{Ma} \mathrm{N}, \mathrm{Fu} \mathrm{Q}$, Hong Y, et al. Processing natural wood into an efficient and durable solar steam generation device. ACS Appl Mater Interfaces, 2020, 12: 18165-18173

35 Liu N, Hao L, Zhang B, et al. Rational design of high-performance bilayer solar evaporator by using waste polyester-derived porous carbon-coated wood. Energy Environ Mater, 2021, eem2.12199

36 Ni F, Xiao P, Zhang C, et al. Micro-/macroscopically synergetic control of switchable $2 \mathrm{D} / 3 \mathrm{D}$ photothermal water purification enabled by robust, portable, and cost-effective cellulose papers. ACS Appl Mater Interfaces, 2019, 11: 15498-15506

37 Wang $\mathrm{Y}, \mathrm{Wu} \mathrm{X}, \mathrm{Gao} \mathrm{T}$, et al. Same materials, bigger output: A reversibly transformable $2 \mathrm{D}-3 \mathrm{D}$ photothermal evaporator for highly efficient solar steam generation. Nano Energy, 2021, 79: 105477

38 Chao W, Li Y, Sun X, et al. Enhanced wood-derived photothermal evaporation system by in-situ incorporated lignin carbon quantum dots. Chem Eng J, 2021, 405: 126703

39 Kim K, Yu S, An C, et al. Mesoporous three-dimensional graphene networks for highly efficient solar desalination under 1 sun illumination. ACS Appl Mater Interfaces, 2018, 10: 15602-15608

40 Gong J, Chen X, Tang T. Recent progress in controlled carbonization of (waste) polymers. Prog Polym Sci, 2019, 94: 1-32

41 Hao L, Liu N, Zhang B, et al. Waste-to-wealth: Sustainable conversion of polyester waste into porous carbons as efficient solar steam generators. J Taiwan Institute Chem Engineers, 2020, 115: 71-78

42 Yang Y, Liu Y, Li Y, et al. Design of compressible and elastic N-doped porous carbon nanofiber aerogels as binder-free supercapacitor electrodes. J Mater Chem A, 2020, 8: 17257-17265

43 Gao Y, Xiao Z, Kong D, et al. N,P co-doped hollow carbon nanofiber membranes with superior mass transfer property for trifunctional metal-free electrocatalysis. Nano Energy, 2019, 64: 103879

44 Song C, Hao L, Zhang B, et al. High-performance solar vapor generation of $\mathrm{Ni} /$ carbon nanomaterials by controlled carbonization of waste polypropylene. Sci China Mater, 2020, 63: 779-793

45 Zhang $\mathrm{P}, \mathrm{Xu} \mathrm{Q}$, Liao Q, et al. Interface-enhanced distillation beyond tradition based on well-arranged graphene membrane. Sci China Mater, 2020, 63: 1948-1956

46 Wilson HM, Rahman A.R. S, Parab AE, et al. Ultra-low cost cotton based solar evaporation device for seawater desalination and waste water purification to produce drinkable water. Desalination, 2019, 456: 85-96

47 Wang $\mathrm{Y}, \mathrm{Wu} \mathrm{X}$, Yang X, et al. Reversing heat conduction loss: Extracting energy from bulk water to enhance solar steam generation. Nano Energy, 2020, 78: 105269

48 Wang $\mathrm{Y}, \mathrm{Wu} \mathrm{X}$, Shao B, et al. Boosting solar steam generation by structure enhanced energy management. Sci Bull, 2020, 65: 1380-1388

$49 \mathrm{Wu} \mathrm{X}, \mathrm{Wu} \mathrm{Z}$, Wang $\mathrm{Y}$, et al. All-cold evaporation under one sun with zero energy loss by using a heatsink inspired solar evaporator. Adv Sci, 


\section{1, 8: 2002501}

50 Gao M, Peh CK, Zhu L, et al. Photothermal catalytic gel featuring spectral and thermal management for parallel freshwater and hydrogen production. Adv Energy Mater, 2020, 10: 2000925

51 Shao B, Wang Y, Wu X, et al. Stackable nickel-cobalt@polydopamine nanosheet based photothermal sponges for highly efficient solar steam generation. J Mater Chem A, 2020, 8: 11665-11673

52 Song C, Zhang B, Hao L, et al. Converting poly(ethylene terephthalate) waste into $\mathrm{N}$-doped porous carbon as $\mathrm{CO}_{2}$ adsorbent and solar steam generator. Green Energy Environ, 2020, doi: 10.1016/j.gee.2020.10.002

53 Guo X, Gao H, Wang S, et al. Scalable, flexible and reusable graphene oxide-functionalized electrospun nanofibrous membrane for solar photothermal desalination. Desalination, 2020, 488: 114535

54 Guo D, Yang X. Highly efficient solar steam generation of low cost TiN/bio-carbon foam. Sci China Mater, 2019, 62: 711-718

55 Meng S, Zhao X, Tang CY, et al. A bridge-arched and layer-structured hollow melamine foam/reduced graphene oxide composite with an enlarged evaporation area and superior thermal insulation for highperformance solar steam generation. J Mater Chem A, 2020, 8: 27012711

56 Liang $\mathrm{H}$, Liao Q, Chen $\mathrm{N}$, et al. Thermal efficiency of solar steam generation approaching $100 \%$ through capillary water transport. Angew Chem Int Ed, 2019, 58: 19041-19046

57 Guan QF, Han ZM, Ling ZC, et al. Sustainable wood-based hierarchical solar steam generator: A biomimetic design with reduced vaporization enthalpy of water. Nano Lett, 2020, 20: 5699-5704

58 Sun Z, Li W, Song W, et al. A high-efficiency solar desalination evaporator composite of corn stalk, Mcnts and $\mathrm{TiO}_{2}$ : ultra-fast capillary water moisture transportation and porous bio-tissue multi-layer filtration. J Mater Chem A, 2020, 8: 349-357

59 Dong Z, Zhang C, Peng H, et al. Modular design of solar-thermal nanofluidics for advanced desalination membranes. J Mater Chem A, 2020, 8: 24493-24500

60 Wang Z, Wu X, He F, et al. Confinement capillarity of thin coating for boosting solar-driven water evaporation. Adv Funct Mater, 2021, 31: 2011114

61 Qiao L, Li N, Luo L, et al. Design of monolithic closed-cell polymer foams via controlled gas-foaming for high-performance solar-driven interfacial evaporation. J Mater Chem A, 2021, 9: 9692-9705

62 Liu N, Hao L, Zhang B, et al. High-performance solar vapor generation by sustainable biomimetic snake-scale-like porous carbon. Sustain Energy Fuels, 2020, 4: 5522-5532

63 He P, Hao L, Liu N, et al. Controllable synthesis of sea urchin-like carbon from metal-organic frameworks for advanced solar vapor generators. Chem Eng J, 2021, 423: 130268

Acknowledgements This work was financially supported by the National Natural Science Foundation of China (51903099 and 51991353), Huazhong University of Science and Technology (3004013134 and 2021XXJS036), the 100 Talents Program of the Hubei Provincial Government, and the Innovation and Talent Recruitment Base of New Energy Chemistry and Device (B21003). We are grateful to the Analytical and Testing Centre of HUST for access to their facilities.

Author contributions Hao L, Gong J, and Tang T designed and engineered the samples; Hao L and Liu N performed the experiments; Hao L wrote the paper with support from Gong J; Gong J, Tang T, and Niu R revised the manuscript. All authors contributed to the general discussion.

Conflict of interest The authors declare that they have no conflict of interest.

Supplementary information Experimental details and supporting data are available in the online version of the paper.

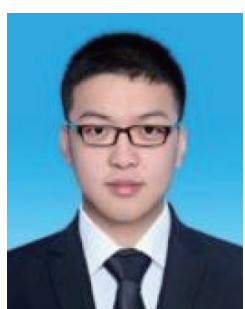

Liang Hao received his MSc degree from Zhejiang University of Technology in 2019. He is now a PhD student in Prof. Jiang Gong's group at Huazhong University of Science and Technology, focusing on the fabrication of carbon materials from polymers for solar evaporation.

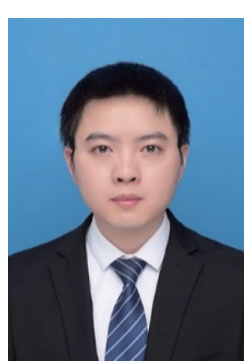

Jiang Gong received his BSc degree at Sichuan University (2010) and $\mathrm{PhD}$ degree from Changchun Institute of Applied Chemistry, Chinese Academy of Sciences (CAS) (2015) under the supervision of Prof. Tao Tang. He was a postdoctoral fellow at Max Planck Institute of Colloids and Interfaces with Prof. Markus Antonietti and Prof. Jiayin Yuan (20152017), and the University of Texas at San Antonio with Prof. Banglin Chen (2017-2018). From 2018, he has been a full Professor of Huazhong University of Science and Technology. His current research includes the synthesis of carbon materials for solar evaporation, photocatalysis, and energy storage.

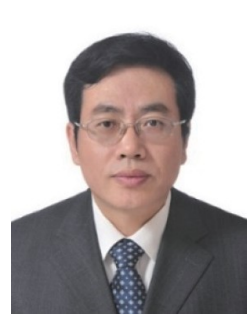

Tao Tang received his BSc degree at Dalian University of Technology (1985), MS Degree at the East China University of Science and Technology (1988) and $\mathrm{PhD}$ degree at Changchun Institute of Applied Chemistry (CIAC), CAS (1991). He worked at CIAC as research associate (1992-1994), associate professor (1994-1997) and full professor (1997-present). His research interests include polymer nanocomposite and foaming, the carbonization and application of polymer materials, and controllable synthesis of polymers with different chain architectures.

\section{基于柔性多孔碳/纸浆纤维膜的高性能耐盐太阳能界 面蒸发}

郝亮 $^{1}$, 刘 $^{1}{ }^{1}$, 牛再 ${ }^{1}$, 龚江 ${ }^{1 *}$, 唐涛 $^{2 *}$

摘要 太阳能蒸发是利用太阳能进行淡水生产和海水淡化的一项极具 吸引力的技术. 然而, 开发柔性高、成本低、耐盐性好的高效太阳能蒸 汽发生器仍然是一个巨大的挑战. 本文利用多孔碳和商业纸浆纤维材 料, 通过简单抽滤来制备柔性、耐用的太阳能光热膜. 结构明确的多孔 碳利用熔融盐对生物质/废塑料进行可控碳化制备. 我们证明了多孔碳 和纸浆纤维在提高太阳能蒸汽性能方面具有协同效应. 首先, 多孔碳表 现出优异的光吸收性能和光热效应, 而亲水性的纸浆纤维则能有效地 输送水分. 其次, 多孔碳的纳米孔与纸浆纤维的亲水基团相结合, 使水 的蒸发焓降低了 $20 \%$, 这是提高蒸发性能的关键. 比如, 在 $1 \mathrm{~kW} \mathrm{~m}^{-2}$ 辐照 下, 多孔碳/纸浆纤维复合膜的蒸发速率高达 $1.8 \mathrm{~kg} \mathrm{~m}^{-2} \mathrm{~h}^{-1}$. 此外, 纸浆 纤维良好的柔韧性和机械性能使复合膜在极端条件下(例如, 经过 20 次 折叠/拉伸(恢复)处理后仍然表现出非常好的性能. 最后, 得益于超亲水 性和超湿润性, 复合膜在连续海水淡化过程中表现出优异的耐盐性和 长期稳定性. 本文还开发了一种用于室外实验的大型太阳能海水淡化 装置, 用于生产淡水. 因此, 这项工作为开发先进的柔性太阳能蒸发器 提供了新的策略. 